\title{
SSynthesis
}

International Scientific Conference of IT and Business-Related Research

\section{EMPIRIJSKA ANALIZA VALIDNOSTI OKUNOVOG ZAKONA NA TRŽIŠTU MAKEDONIJE}

\author{
THE EMPIRICAL ANALYSIS OF OKUN'S LAW \\ ON THE MACEDONIAN MARKET
}

\author{
Vesna Prorok \\ Ekonomski fakultet Pale, Univerzitet u Istočnom Sarajevu, Republika Srpska
}

\begin{abstract}
Apstrakt:
Cilj ovog rada je provera validnosti Okunovog zakona, kao i ispitivanje postojanja dugoročne i kratkoročne veze između stope rasta BDP-a i stope nezaposlenosti na tržištu Makedonije u periodu od 1991. do 2009. godine. Analiza je izvršena primenom Engle-Grangerovog testa kointegracije za proveru postojanja dugoročnog slaganja između varijabli, dok je mehanizam korekcije greške (ECM) korišćen za utvrđivanje njihove kratkoročne dinamike. Empirijska analiza ukazala je na to da je Okunov zakon neprihvatljiv za tržište Makedonije u posmatranom periodu, te da je dugoročna veza između varijabli pozitivna u oba smera, dok kratkoročna veza, koja je takođe pozitivna, postoji samo iz pravca stope rasta BDP-a.
\end{abstract}

\section{Ključne reči:}

stopa rasta BDP-a, stopa nezaposlenosti, Engle-Grangerov test kointegracije, mehanizam korekcije greške.

\section{UVOD}

Okunov zakon kao jedan od osnovnih makroekonomskih postulata, po prvi put je uveden u makroekonomsku teoriju 1960-ih godina od strane Artura Okuna iz Instituta Brukings u Vašingtonu. Zakon se zasnivao na empirijskim istraživanjima veze između stope nezaposlenosti i ostvarenih gubitaka $u$ nivou bruto domaćeg proizvoda sprovedenim na uzorcima podataka iz različitih vremenskih perioda velikog broja zemalja, primjenom različitih statističkih metoda. Kao takav, zakon je vremenom postao kako standardni alat tržišnih analitičara i teoretičara, tako i dobar vodič za kreatora ekonomske i monetarne politike, jer pruža odgovor na pitanje kako će se promjene u nivou bruto domaćeg proizvoda odraziti na nivo nezaposlenosti u okviru ekonomije jedne zemlje.

Okunov zakon, u literaturi poznat i kao Okunovo pravilo palca, ukazuje na postojanje negativne, odnosno inverzne veze između proizvodnje i nezaposlenosti. Originalni Okunov zakon polazi od stanovišta da pad od približno $2 \%$ inflatorno-prilagođenog bruto domaćeg proizvoda prouzrokuje rast stope nezaposlenosti u iznosu od oko $1 \%$. Drugim riječima, svako povećanje realnog BDP-a za oko $1 \%$, vodiće padu stope nezaposleni za približno pola procentnog poeana.

Zbog istorijske stabilnosti Okunovog zakona u Sjedinjenim Američkim Državama, ekonomisti su često koristili stopu nezaposlenosti za ocjenu svojih budućih predviđanja (Daly et al., 2014.). Međutim, ovakav razuman pristup, koji je podrazumijevao da se rast BDP-a i promjene stope nezaposlenosti kreću

\section{Abstract:}

The purpose of this paper is to estimate the validity of Okun's law, and to test the existence of long-term and short-term relationship between the growth rate of GDP and unemployment rate in Macedonia in the period from 1991 to 2009 . The analysis was performed using the Engle-Granger cointegration test to verify the existence of the longterm correlation between the variables, while the Error Correction Mechanism (ECM) is used for determining their short-term dynamics. The empirical analysis indicates that the Okun's law is unacceptable for the Macedonian market during the analyzed period, and that the long-run relationship between the variables is positive in both directions, while the short-term relationship, which is also positive, exists only from the direction of the GDP growth rate.

\section{Key words:}

GDP growth rate, unemployment rate, Engle-Granger cointegration test, Error Correction Mechanism.

zajedno u omjeru 2:1, činilo se da se ruši tokom velike ekonomske i finansijske krize koje je pogodila sve svjetske ekonomije već u prvoj deceniji ovog vijeka. Takva dešavanja pokrenula su raspravu o stabilnosti Okunovog zakona u uslovima krize, pogotovo u zemljama u razvoju i slabo razvijenim zemalja, u kojima su se posljedice krize, nesumnjivo, najviše i osjetile. Ovakva dešavanja potvrdila su činjenicu da Okunov zakon predstavlja samo statističku vezu između ove dvije pojave prije nego strukturnu karakteristiku ekonomije jedne zemlje. Iz tog razloga, kao i svaki drugi statistički odnos, često predstavlja predmet revizije, pogotovo u ekonomijama koje su izložene „neočekivano” velikim fluktuacijama u pogledu bilo koje makroekonomske varijable za koje se uglavnom, u ne tako efikasnim uslovima, teško pronalazi rješenje.

U ovom radu pokušaće se dati odgovor na dva pitanja: da li Okunov zakon predstavlja stabilan odnos između rasta BDP-a i promjene stope nezaposlenosti u zemljama u tranziciji, kao što je Makedonija i u kojoj mjeri on predstavlja koristan mehanizam za buduća ekonomska predviđanja?

Cilj rada je da se na bazi godišnjih podataka o stopi rasta BDP-a i promjene stope nezaposlenosti u periodu od 1991. do 2009. godine provjeri validnost Okunovog zakona na tržištu Makedonije. Drugim riječima, testiraće se da li na makedonskom tržištu između ove dvije pojave postoji dugoročna i kratkoročna veza, a zatim će se, u slučaju da takve veze postoje, utvrditi nivo njihovog intenziteta i pravac djelovanja. Na osnovu rezultata sprovedene analize uočiće se sličnost između tržišta Makedonije i ostalih tranzicionih zemalja Zapadnog Balkana. 
U ekonomskoj teoriji poznata su tri pristupa ili verzije Okunovog zakona: 1) verzija diferencija, 2) verzija jaza ili gapa i 3) verzija zakona proizvodne funkcije (Javeid, 2012). Zbog njene jednostavnosti, u radu ćemo koristi verziju diferencija koja se može direktno primijeniti na ekonomske serije podataka kojima raspolažemo. $U$ analizi su korišteni podaci iz dostupne baze podataka Svjetske banke. Testiranje postojanja dugoročne veze između stope rasta BDP-a i promjene stope nezaposlenosti izvršiće se primjenom Engle-Grangerovog testa kointegracije, dok će se, za slučaj da je kointegracije prisutna, pristupiti formiranju mehanizma korekcije greške (Error Correction Mechanism) kojim bi se uočili kratkoročni efekti između pomenutih varijabli. Za utvđivanje nivoa stacionarnosti vremenskih serija posmatranih varijabli, te za testiranje stacionarnosti reziduala formiranih regresionih modela, koristiće se prošireni Dickey-Fullerov test (Augmented Dickey-Fuller test), a zaključci će se donositi na bazi nivoa značajnosti od $5 \%$.

\section{PREGLED LITERATURE}

Svjetska ekonomska i finansijska kriza iz 2008. godine u velikoj mjeri se negativno odrazila na privredne sisteme kako vodećih svjetskih ekonomija, tako i zemalja u razvoju i slabo razvijenih zemalja. Njeni efekti brzo su se prenijeli i na tržište rada koje je, nesumnjivo, bilo izloženo najvećim fluktuacija u posljednjoj deceniji. Ovakva dešavanja podstakla su da veza između stope rasta BDP-a i promjene stope nezaposlenosti postane predmet istraživanja velikog broja ekonomskih i finansijskih analitičara koji su u nastojanju da predvide buduća kretanja ključnih makroekonomskih varijabli, bili primorani da ispitaju validnost nekih osnovnih makroekonomskih zakonitosti. S obzirom na činjenicu da nezaposlenost predstavlja najveći svjetski ekonomski i socijalni problem, najveću pažnju stručne javnosti je, s razlogom, privuklo tržište rada. Ovdje ćemo se kratko osvrnuti samo na neka od istraživanja sprovedenih na američkim, azijskim i evropskim tržištima u posljednjoj deceniji, a koja se odnose na provjeru validnosti Okunovog zakona koji, kao jedan od osnovih makroekonomskih zakona, ukazuje na inverzni karakter veze između stope rasta BDP-a i promjene stope nezaposlenosti.

Umer Javeid je u radu Validity of Okun's Law: Empirical Evidence from Pakistan (1981-2005) testirao kako validnost Okunovog zakona, tako i postojanje dugoročne i kratkoročne veze između stope nezaposlenosti i stope rasta BDP-a u Pakistanu, na bazi godišnjih podataka u periodu od 1981. do 2005. Treba napomenuti da se korišćenjem podataka u dužem vremenskom periodu smanjuje mogućnost pojave devijacije u rezultatima. Primjenjujući verziju diferencija Okunovog zakona Javeid je došao do zaključka da između dvije pomenute varijable postoji negativna, odnosno inverzna veza. Vrijednost Okunovog koeficijenta iznosila je $2,8 \%$ što se objašnjava time da rast BDP-a $\mathrm{u}$ iznosu od $1 \%$ prouzrokuje smanjenje stope nezaposlenosti u iznosu od 2,8\%, dok se vrijednost konstante od 0,192 definiše kao stopa nezaposlenosti pri nultoj promjeni stope rasta BDPa. S druge strane, posmatrano u kratkoročnom vremenskom periodu, primjenom mehanizma korekcije greške (Error Correction Mechanism), došlo se do zaključka da ekonomski rast od $1 \%$ prouzrokuje smanjenje stope nezaposlenosti u iznosu od $3,1 \%$. Ova analiza je u velikoj mjeri potvrdila validnost Okunovog zakona na tržištu Pakistana. Međutim, slična analiza koja je obuhvatila više azijskih tržišta (Pakistan, Indija, Kina, Šri Lanka i Bangladeš) u periodu od 1980. do 2006. godine ukazala je na mješovite rezultate u pogledu vrijednosti Okunovog koeficijenta (Lal et al., 2010).
Julien Fouquan (2012) je na panel seriji podataka koja je uključivala 20 OECD zemalja u periodu od posljednje tri decenije, nastojao da dokaže da Okunov zakon ne predstavlja linearnu vezu između stope nezaposlenosti i stope rasta BDP-a. Kao prvo, u radu je bila primijenjena Hensenova metodologija koja je omogućila da se pokaže prisustvo efekata praga u Okunovom zakonu, bez obzira na metod dekompozicije rezultata i izabrane varijable praga. Rezultati istraživanja ukazali su na postojanje asimetrije u vezi između ciklične nezaposlenosti i jaza u proizvodnji. S druge strane, ova studija pružila je originalni pristup grupisanju podataka iste dinamike kojim se rješava problem hetegorenosti, te uvođenju Okunovog zakona za koji se potvrdilo da tokom vremena varira.

Sličnu analizu sproveo je Bilal Kargi (2013) analizirajući validnost Okunovog zakona na 34 zemlje OECD-a. Analiza je pokazala da je veza između stope rasta BDP-a i stope nezaposlenosti inverznog karaktera, te da kointegracija postoji, posmatrano u dugom roku. $\mathrm{U}$ okviru ove studije zemlje su kategorizovane prema stopi rasta BDP-a na one koje imaju nisku, normalnu i visoku stopu rasta. Konzistentnost u pogledu stope nezaposlenosti za zemlje sa visokom stopom rasta nije uočena, dok se u slučaju zemalja sa niskim stopama rasta došlo do generalnog zaključka da su stope nezaposlenosti izuzetno visoke.

\section{METODOLOGIJA I ANALIZA}

U radu će se hipoteza postojanja kointegracije stope raste BDP-a i stope nezaposlenosti u Makedoniji, testirati na bazi kretanja istorijskih godišnjih podataka pomenutih varijabli u periodu od 1991. do 2009. godine.

Na grafikonu 1 predstavljene su vremenske serije kretanja godišnjih stopa rasta BDP-a i stope nezaposlenosti u Makedoniji u okviru analiziranog vremenskog perioda.

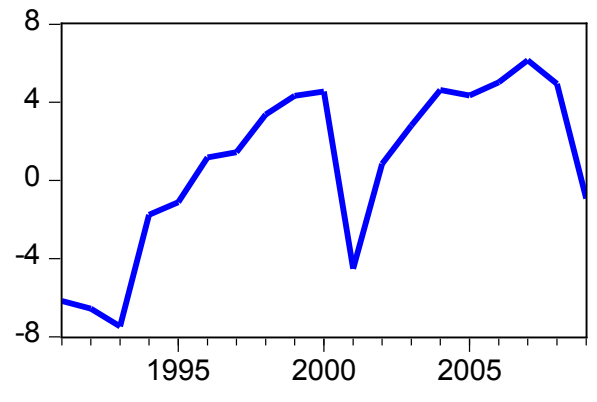

- Stopa rasta BDP-a

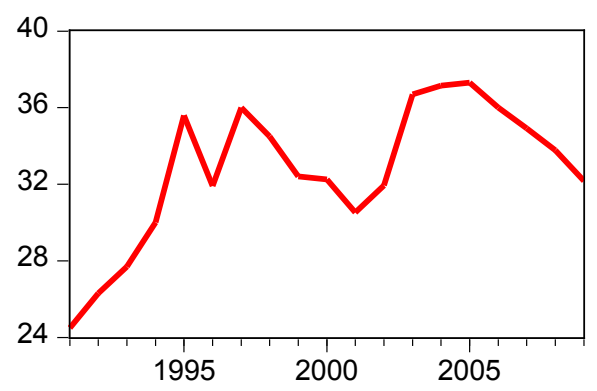

Stopa nezaposlenosti

Grafik 1. Grafički prikaz godišnjih stopa rasta BDP-a i stopa nezaposlenosti u Makedoniji u periodu od 1991. do 2009. godine 


\subsection{TEST JEDINIČNOG KORENA}

Za svaku prikazanu vremensku seriju utvrđen je nivo stacionarnosti primjenom proširenog Dicky-Fullerovog testa (ADF test) jedičnog korena. Za određivanje optimalnog broja lagova autoregresionog modela vremenske serije za koju se utvrđuje nivo stacionarnosti, korišten je Švarcov kriterijum. Treba napomenuti da pored Švarcovog postoji niz drugih kriterijuma za utvrđivanjem optimalnog broja lagova u autoregresionom modelu. Neki od tih kriterijuma polaze od unaprijed razumno određenog maksimalnog broja lagova koji se postepeno testiranjem smanjuje, dok se ne dođe do broja pri kome su svi lagovi statistički značajni. Takođe, postoje i kriterijumi koji polaze od minimalno mogućeg broja lagova, te se svaki put vrši testiranje reziduala da bi se ustanovilo da li između njih postoji autorkorelacija. Postojanje autokorelacije između reziduala ukazuje na potrebu da se broj lagova poveća, pri čemu se postupak ponavlja sve dok se ne dođe do optimalnog broja lagova u autoregresionom modelu. Drugim riječima, dodavanje lagova prestaje onog momenta kada je svako postojanje autokorelacije između reziduala uklonjeno (Mahadeva \& Robinson, 2004).

Prošireni Dickey-Fullerov test jediničnog korjena podrazumijeva izraze oblika:

$$
\begin{aligned}
& \Delta y_{t}=\gamma y_{t-1}+\sum_{p=1}^{p} \phi_{p} \Delta y_{t-p}+\varepsilon_{t}, \\
& \Delta y_{t}=\phi_{0}+\gamma y_{t-1}+\sum_{p=1}^{p} \phi_{p} \Delta y_{t-p}+\varepsilon_{t}, \\
& \Delta y_{t}=\phi_{0}+\delta_{1} t+\gamma y_{t-1}+\sum_{p=1}^{p} \phi_{p} \Delta y_{t-p}+\varepsilon_{t}
\end{aligned}
$$

koji obuhvataju test jediničnog korena, test jediničnog korena sa uključenom konstantom, te test jediničnog korena sa uključenom konstantom i linearnim trendom. Nulta hipoteza koja se provjerava je hipoteza nestacionarnosti, odnosno postojanja jediničnog korena u vremenskoj seriji, što podrazumijeva da je koeficijent $\gamma=0$. Ako bi distribucija $\hat{\gamma}$ posjedovala standardni normalan raspored pri provjeri nulte hipoteze, onda bi ovakav test bio veoma jednostavan. Međutim, raspored $\hat{\gamma}$ u okviru nulte hipoteze nije standardni normalan, jer $\gamma_{t-1}$ je jedinični koren i varijansa takvog procesa raste kako se broj opservacija povećava (Sheppard, 2012). Iz tog razloga prilikom donošenja zaključka o vrijednosti $t$ testa, neophodno je, umjesto standardizovanog normalnog, koristiti Dickey-Fullerov raspored. Rezultat proširenog Dickey-Fullerovog testa ukazuju na prihvatanje ili odbijanje nulte hipoteze. U slučaju da je nulta hipoteza odbijena, prihvata se alternativna hipoteza o stacionarnosti vremenske serije $(\gamma<0)$ za podatke na nivou, dok prihvatanje nulte hipoteze vodi tome da se postupak testiranja nastavlja za diferenciranu seriju podataka, sve dok se ne dođe do nivoa diferencije na kome je uslov stacionarnosti ispunjen. Jednačine oblika

$$
\begin{aligned}
& \Delta^{2} y_{t}=\gamma \Delta y_{t-1}+\sum_{p=1}^{p} \phi_{p} \Delta^{2} y_{t-p}+\varepsilon_{t}, \\
& \Delta^{2} y_{t}=\phi_{0}+\gamma \Delta y_{t-1}+\sum_{p=1}^{p} \phi_{p} \Delta^{2} y_{t-p}+\varepsilon_{t}, \\
& \Delta^{2} y_{t}=\phi_{0}+\delta_{1} t+\gamma \Delta y_{t-1}+\sum_{p=1}^{p} \phi_{p} \Delta^{2} y_{t-p}+\varepsilon_{t}
\end{aligned}
$$

su jednačine koje obuhvataju diferenciranu serije podataka prvog nivoa, gdje će primjena Dickey-Fullerovog testa jediničnog korena, za većinu ekonomskih varijabli, ukazati na postojanje stacionarnosti vremenske serije. U nastavku će se pokazati da su i vremenske serije stope rasta BDP-a i promjene stope nezaposlenosti, koji su predmet analize ovog rada, takođe stacionarne na prvom nivou $I(1)$.

U Tabeli 2. rezultati ADF testa pokazuju da ni jedna od testiranih varijabli nije stacionarna na nivou uz nivo značajnosti $5 \%$. Međutim, stacionarnost za sve testirane varijable je postignuta za diferencirane serije podataka na prvom nivou, što predstavlja osnovu za upotrebu Engle-Grangerovog testa kointegracije.

\begin{tabular}{|c|c|c|}
\hline Varijable & ADF & I(d) \\
\hline GDPGR & $-2,164126$ & $\mathrm{I}(1)$ \\
\hline $\mathrm{d}(\mathrm{GDPGR})$ & $-4,206577^{*}$ & $\mathrm{I}(0)$ \\
\hline $\mathrm{UNR}$ & $-2,657973$ & $\mathrm{I}(1)$ \\
\hline $\mathrm{d}(\mathrm{UNR})$ & $-4,294173^{*}$ & $\mathrm{I}(0)$ \\
\hline
\end{tabular}

Tabela 2: Rezultati ADF testa jediničnog korjena za pojedične vremenske serije posmatranih varijabli

U tabeli 2. varijabla GDPGR je stopa rasta BDP-a, dok je varijabla UNR stopa nezaposlenosti.

\subsection{ENGLE-GRANGEROV TEST KOINTEGRACIJE}

Još u drugoj polovini prošlog vijeka, pojava lažne regresije kao posljedica nestacionarnosti vremenskih serija koje su bile predmet regresione analize, predstavljala je glavni problem empirijskih analitičara. Neki istraživači su rješenje problema pronašli u regresionoj analizi diferenciranih serija podataka, $s$ tim da se diferenciranje vršilo do onog nivoa dok se ne postigne stacionarnost vremenske serije. Međutim, ovakva rješenja brzo su naišla na kritiku, jer se ustanovilo da regresiona analiza na diferenciranim podacima dovodi do gubitka veoma značajnih dugoročnih informacija sadržanih u stvarnoj seriji.

Veliki zaokret u izučavanju analize vremenskih serija napravio je Granger kada je 1981. godine u teoriju prvi put uveo koncept kointegracije. Nedugo zatim Engle i Granger su 1987. godine predstavili čvrstu teorijsku osnovu za testiranje, ocjenu i modeliranje kointegracije nestacionarnih vremenskih serija. Kointegraciona analiza dozvoljava da se nestacionarne vremenske serije koriste na način da lažna regresija bude izbjegnuta. Ovakav pristup omogućio je analitičarima da testiraju dugoročnu vezu između varijabli na bazi stvarnih vrijednosti vremenskih serija.

Treba napomenuti da se Engle-Grangerov test kointegracije koristi za varijable koje su stacionarne na istom nivou, dok se za varijable različitih nivoa stacionarnosti uglavnom koristi Johansenov test kointegracije. U slučaju analiziranja postojanja kointegracije između više varijabli, Engle-Grangerov test pokazuje svoje nedostatke, tj. ne obezbjeđuje informaciju o broju kointegracionih veza, već samo informaciju o tome da li je kointegracija prisutna ili ne. Međutim, u našem primjeru gdje se razmatra postojanje kointegracije samo između dvije varijable, stope rasta BDP-a i promjene stope nezaposlenosti, primjena Engle-Grangerov testa nesumnjivo će obezbijediti zadovoljavajuće rezultate.

Engle-Grangerova procedura sastoji se od ocjene kointegracione regresije u oba smjera metodom najmanjih kvadrata. Drugim riječima, potrebno je formirati dva kointegraciona regresiona modela oblika: 


$$
\begin{aligned}
& G D P G R_{t}=\beta_{0}+\beta_{1} U N R_{t}+e_{t} \\
& U N R_{t}=\beta_{0}+\beta_{1} G D P G R_{t}+e_{t}
\end{aligned}
$$

$\mathrm{U}$ prvom se ispituje zavisnost stope rasta BDP-a od promjene stope nezaposlenost, a u drugom zavisnost promjene stope nezaposlenosti od stope rasta BDP-a. Nakon ocijenjenih regresionih modela vrši se testiranju stacionarnosti reziduala, da bi se utvrdilo da li između varijabli, posmatrano u oba smjera, postoji kointegracija. Pod kointegracijom se podrazumijeva postojanje dugoročne veze između dvije varijable, spečavajući da vrijednost reziduala $u$ dužem vremenskom periodu postane veća. Testiranje stacionarnosti reziduala vrši se na bazi proširenog Dickey-Fullerovog testa, gdje regresiona jednačina reziduala ima oblik:

$$
\Delta \hat{e}_{t}=\alpha_{1} \hat{e}_{t-1}+\sum_{p=1}^{k} \alpha_{p+1} \Delta \hat{e}_{t-p}+\varepsilon_{t}
$$

Nulta i alternativna hipoteza su iste kao i kod testiranja stacionarnosti vremenskih serija varijabli, gdje će nam rezultat Dickey-Fullerovog testa obezbijedio informaciju o postojanju kointegracije između varijabli. Drugim riječima, prihvatanje nulte hipoteze o postojanju jediničnog korjena reziduala ukazalo bi na nepostanje kointegracije i obrnuto.

U narednoj tabeli dati su rezultati stacionarnosti reziduala dva formirana regresiona modela.

\begin{tabular}{|c|c|c|}
\hline Kointegraciona regresija & $\begin{array}{c}\text { ADF } \\
\text { reziduala }\end{array}$ & $\begin{array}{c}\text { Kritična vrijednost za } \\
\text { nivo značajnosti 5\% }\end{array}$ \\
\hline$G D P G R=-30,77920+0,96512 \cdot U N R$ & $-3,861871^{*}$ & $-3,040391$ \\
$U N R=32,16931+0,687772 G D P G R$ & $-4,205480^{*}$ & $-3,040391$ \\
\hline
\end{tabular}

Razultati su pokali da u oba smjera postoji dugoročno slaganje, odnostno kointegracija kretanja stope rasta BDP-a i stope nezaposlenosti. Međutim, takvo slaganje je pozitivno, što je u suprotnosti sa osnovnom makroekonomskom pretpostavkom o tome da je kretanje ove dvije pojave inverznog karaktera. Takođe, ako bismo testirali validnost Okunovog zakona došli bismo do sličnih rezultata, koji bi potvrdili da Okunov zakon u Makedoniji, kao i u ostalim tranzicionim ekonomijama Zapadnog Balkana, ne važi.

Verzija diferencije Okunovog zakona pretpostavlja regresioni model zasnovan na promjenama vrijednosti varijabli, odnosno regresioni model $\mathrm{u}$ kome se ispituje zavisnost promjene stope rasta BDP-a u odnosu na promjenu stope nezaposlenosti i obrnuto:

$$
\begin{aligned}
& G D P G R_{t}-G D P G R_{t-1}=\alpha+\beta\left(U N R_{t}-U N R_{t-1}\right)+\varepsilon_{t} \\
& U N R_{t}-U N R_{t-1}=\alpha+\beta\left(G D P G R_{t}-G D P G R_{t-1}\right)+\varepsilon_{t}
\end{aligned}
$$

gdje je $\alpha$ konstanta, a $\beta$ Okunov koeficijent za koji se pretpostavlja da ima negativnu vrijednost kao posledica inverznog odnosa kretanja promene stope rasta BDP-a i promene stope nezaposlenosti, na način koji je definisan Okunovim zakonom. U sprovedenoj analizi vrijednost Okunovog koeficijenta za oba modela iznosi 0.383248 i 0.212714 , respektivno. To bi značilo da rezultati empirijske analize nisu u saglasnosti sa makroekonomskom teorijom na tržitu Makedonije. Drugim riječima, nije ispunjena validnost Okunovog zakona, s obzirom na to da je vrijednost koeficijenata pozitivna, te da nijedan od koeficijenata nije statistički značajan.
Ovakav rezultat ekonomski je i opravdan u okviru skoro svih tranzicionih zemalja Zapadnog Balkana, pogotovo ako se uzme u obzir činjenica da je ekonomski rast u periodu prije krize 2008. godine bio posledica velikog priliva slobodnog inostranog kapita, koji nije bio iskorišćen za obnovu realnog sektora kao nosioca svake zdrave ekonomije, već naprotiv, uglavnom za finansiranje neuspješne reforme vlasničkih odnosa. Nerazvijen realni sektor vodio je nedovoljnoj iskorišćenosti ljudskih resursa, što je vremenom preraslo u hronični problem, naročito u periodu poslije krize, kada su se inostrani prilivi kapitala pokazali kao neodrživi.

Kako su rezultati pokazali postojanje kointegracije između stope rasta BDP-a i stope nezaposlenosti, potrebno je pristupiti primjeni mehanizma korekcije greške (Error Correction Mechanism) da bi se utvrdilo da li između ove dvije varijable postoji kratkočno slaganje u njihovom kretanju.

\subsection{MEHANIZAM KOREKCIJE GREŠKE (ECM-ERROR CORRECTION MECHANISM)}

Mehanizam korekcije greške je dinamički sistem koji se zasniva na tome da se odstupanja trenutnog stanja pojave od njene dugoročne veze mogu ugraditi u njenu kretkoročnu dinamiku. Model korekcije greške ne predstavlja model kojim se ispravlja greška u nekom drugom modelu, već je to kategorija modela koji su sačinjeni od više vremenskih serija na osnovu kojih se direktno utvđuje brzina pri kojoj se zavisno promjenljiva vraća u svoj ravnotežni položaj kao posljedica promjene vrijednosti nezavisno promjenljive.

Empirijski, za oba modela, ovo se može prikazati u obliku jednačina:

$$
\begin{aligned}
& G D P G R_{t}-G D P G R_{t-1}=\theta_{0}+\theta_{1} \hat{e}_{t-1}^{*}+\lambda_{1}\left(U N R_{t}-U N R_{t-1}\right)+\varepsilon_{t} \\
& U N R_{t}-U N R_{t-1}=\theta_{0}+\theta_{1} \widehat{e}_{t-1}^{*}+\lambda_{1}\left(G D P G R_{t}-G D P G R_{t-1}\right)+\varepsilon_{t}
\end{aligned}
$$

gdje je:

$\widehat{e}_{t-1}^{*}=G D P G R_{t-1}-\beta_{0}-\beta_{1} U N R_{t-1}$ za prvi model,

$\widehat{e}_{t-1}^{*}=U N R_{t-1}-\beta_{0}-\beta_{1} G D P G R_{t-1}$ za drugi model.

U slučaju da su vrijednosti $\widehat{e}_{t-1}^{*}$, u oba modela, različite od nule, varijable GDPGR i $U N R_{t}$, respektivno, se nalaze izvan svoje dugoročne ravnoteže.

Ocijenjeni prethodni modeli imaju oblik:

$G D P G R_{t}-G D P G R_{t-1}=0.200543-0.977577 \bar{e}_{t-1}^{*}+0.365819\left(U N R_{t}-U N R_{t-1}\right)$ $U N R_{t}-U N R_{t-1}=0.24909-0.81141 \widehat{e}_{t-1}^{*}+0.509144\left(G D P G R_{t}-G D P G R_{t-1}\right)$

U prvom modelu, vrijednost $\theta_{1}$ je statitički značajna i iznosti -0.977577 , što bi značilo da se tekuća vrijednost stope rasta BDP-a prilagođava svojoj ravnotežnoj vrijednosti brzinom od 0.977577 pomnoženom sa iznosom odstupanja u prethodnom periodu. Isti zaključak se može izvesti i za vrijednost $\theta_{1}$ drugog modela. S druge strane, koeficijent $\lambda_{1}$ ukazuje na kratkoročne varijacije zavisne varijable kao rezultat promjene tekuće vrijednosti nezavisne varijable. U oba modela, vrijednosti ovih koeficijenata su pozitivne, ali samo u drugom modelu koeficijent $\lambda_{1}$ je statistički značajan. Na onovu toga se može zaključiti da kratkoročni uticaj jedne varijable na drugu, dolazi samo iz pravca stope rasta BDP-a i odražava se na stopu nezaposlenosti. Ovo je samo još jedna potvrda da se veza između stope rasta BDPa i stope nezaposlenosti, kako dugoročna, tako i kratkoročna, 
na tržištu Makedonije, protivi osnovnom maktroekonomskom principu, tj. zakonu da između kretanja stope rasta BDP-a i stope nezaposlenosti postoji inverzan odnos.

\section{ZAKLJUČAK}

Ovaj rad ispituje dugoročnu i kratkoročnu vezu između stope rasta BDP-a i stope nezaposlenosti na tržištu Makedonije u periodu od 1991. do 2009. godine. Rezultati pokazuju da je dugoročna veza između ove dvije varijable pozitivna u oba pravca, dok kratkoročna veza koja je, takođe, pozitivna postoji samo iz pravca stope rasta BDP-a. To bi značilo da se, u posmatranom periodu, pozitivne promjene u stopi rasta BDP-a odražavaju na rast nezaposlenosti na tržištu rada. Takođe, analizom se dovelo u pitanje validnost Okunovog zakona, kao jednog od osnovnih makroekonomskih postulata, te se zaključilo da je takav zakon na tržištu Makedonije, kao i na većini tranzicionih tržišta Zapadnog Balkana, nevažeći.

Sprovedeni rezultati empirijskog istraživanja su realno opravdani, s obzirom na činjenicu da jasno odražavaju sliku ekonomske situacije zemalja Zapadnog Balkana koje su, poslije godina obelježenih sukobima, pristupile obnovi i reformama svojih privrednih sistema. Taj period se karakteriše otvaranjem prema globalnoj ekonomiji, većom orijentacijom prema izvozu, uvođenjem novih zakonskih regulativa kojima se u velikoj mjeri podstakao razvoj malih i srednjih preduzeća, što je naročito bio slučaj u Makedoniji, te izgradnjom institucija za podršku razvoju tržišnog sistema. Uz sve navedeno, te uz uspješnu transformaciju bankarskog sistema, pomoću inostranog kapitala, osigurao se stabilan privredni rast, praćen većim životnim standardom i većom stabilnošću u makroekonomskom pogledu. Međutim, proces reforme privrednih sistema, koji je već u svojim počecima bio suočen sa interesnim grupa, što se posebno uočilo pri sprovođenju procesa privatizacije, zastao je sredinom 2000-tih godina i kao takav još uvijek ostao nedovršen.

Do početka globalne ekonomske i finansijske krize rast na Zapadnom Balkanu bio je više predvođen globalnom likvidnošću i neodrživim prilivom kapitala, nego stvarnim napretkom privrednih reformi (Murgasova et al., 2015). Po pitanju razvoja realnog sektora u tom periodu skoro da nije ništa učinjeno. To je u konačnom vodilo nedovoljnom korišćenju ljudskih resursa, što se vremenom pretvorilo u hronični problem.

S druge strane, visokim stopama nezaposlenosti, koje su daleko nadmašivale visinu prosječne evropske stope nezaposlenosti, doprineli su obimni i konstantni prilivi doznaka iz inostranstva. Najveći iznosi primljenog novca po osnovu doznaka upotrijebljeni su za ličnu potrošnju, dok je samo mali dio priliva produktivno investiran u razvoj. Veliko oslanjanje na doznake, u svrhu lične potrošnje, podiglo je nivo minimalnih plata (za koje su građani bili spremni da rade) iznad nivoa koji je realno mogao biti finansiran i održavan na bazi produktivnosti neefikasnog realnog sektora.

Treba napomenuti da je Makedonija tih godina (1995-2008) i najviše učinila u pogledu restrukturiranja svog privrednog sistema u poređenju sa ostalim zemljama Zapadnog Balkana.
Takvi rezultati se jasno uočavaju u toku proteklog perioda u kome Makadonija bilježi izuzetno visoke stope privrednog rast u poređenju sa ostalim evropskim zemljama, uz postepen, ali konstantan, pad stope nezaposlenosti.

\section{LITERATURA}

Campbell, J. Y., Lo, A. W., \& MacKinlay, A. C. (1997). The econometrics of financial markets. Princeton, N.J: Princeton University Press.

Daly,M.C., Fernald,J., Jorda,O., Nechio,F. (2014). Interpeting Deviations from Okun's Law: FRBSF Economic Letter. Preuzeto 12.02.2015. Sa http://www.frbsf.org/economic-research/publications/economic-letter/2014/april/okun-lawdeviation-unemployment-recession/

Dougherty, C. (2007). Introduction to econometrics. New York: Oxford University Press.

Fouquau, J. (2008). Threshold effects in Okun's law: A panel data analysis. Economics Bulletin, 5(33), 1-14.

Gourieroux, C., \& Jasiak, J. (2001). Financial econometrics: Problems, models, and methods. Princeton, N.J: Princeton University Press.

Javeid, U. (2012). Validity of Okun's Law: Empirical Evidence from Pakistan (1981-2005). Preuzeto 12.02.2015. Sa http:// sh.diva-portal.org/smash/get/diva2:525872/FULLTEXT01. $p d f$

Kargi, B. (2013). Okun's Law and Long Term Co-Integration Analysis for OECD Countries (1987-2012). International Research Journal of Finance and Economics, 119, 77-85.

Lal, I., Muhammad, S. D., Jalil, M. A., \& Hussain, A. (2010) Test of Okun's Law is Some Asian Countries Co-Integration Approach. European Journal of Scientific Research, 40(1), 73-80.

Maddala, G. S. (1992). Introduction to Econometrics. New York: Macmillan Publishing Company.

Mahadeva, L., \& Robinson, P. (2004). Unit Root Testing to Help Model Building. Center for Central Banking Studies, Bank of England

Murgasova, Z., Ilahi, N., Miniane, J., Scott, A., \& Vladkova-Hollar, I. (2015). Zapadni Balkan: 15 godina ekonomske tranzicije. Preuzeto 12.02.2015. Sa https://www.imf.org/external/ pubs/ft/reo/2015/eur/eng/pdf/erei_sr_030915_Serbian.pdf

Sheppard, K. (2012). Financial Econometrics Notes. Preuzeto 12.02.2015. Sa https://www.kevinsheppard.com/images/b/ bb/Financial_Econometrics_2013-2014.pdf

Terrell, D., \& Fomby, T. B. (2006). Econometric analysis of financial and economic time series: Part A. Amsterdam: Elsevier.

Vasiljević, B. (2010). Uticaj doznaka na ekonomski i socijalni razvoj u Srbiji Preuzeto 12.02.2015. Sa http://www.fpn. bg.ac.rs/wp-content/uploads/2010/05/11-Prof.-dr-BrankoVasiljevi\%C4\%87-Uticaj-doznaka-na-ekonomski-i-socijalni-razvoj-u-srbiji.pdf 